\title{
Metastases to the Stomach: Clinicopathologic Features of Metastases Mimicking Gastric Primaries
}

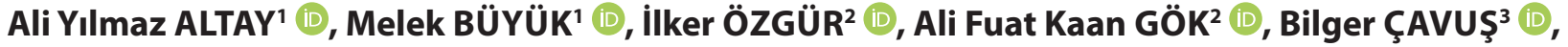 \\ Esra AYDIN ${ }^{4}$, Sezai VATANSEVER ${ }^{4} \mathbb{1}$, Mine GÜLLÜOĞLU ${ }^{\mathbb{D}}$
}

Department of 'Pathology, ${ }^{2}$ General Surgery, ${ }^{3}$ Internal Medicine (Gastroenterology), Istanbul Faculty of Medicine, Istanbul University, ISTANBUL, TURKEY 4Institute of Oncology, Istanbul University, ISTANBUL, TURKEY

\begin{abstract}
Objective: Metastatic involvement of the stomach is a rare event. Our aim in this study was to document the clinicopathological findings in patients with gastric metastases and find out if there are any potentially significant features to be used in the differential diagnosis.
\end{abstract}

Material and Method: Our cohort consisted of 17 histologically verified gastric metastasis cases. Clinical, endoscopic and microscopic features were retrospectively analyzed.

Results: The primary sites were the breast, skin, lungs, ovaries, colon, and gluteal soft tissue. Three patients were symptomatic because of the metastatic involvement of the stomach and 9 patients had concomitant metastasis in other sites. Invasive lobular breast carcinoma and malignant melanoma were the most common metastatic malignancies. The most common macroscopic appearance was the diffuse infiltrative type (Borrmann Type 4). Most of the metastatic lesions endoscopically mimicked primary gastric cancer. Furthermore, some of the metastatic lesions, particularly invasive lobular carcinoma of the breast and malignant melanoma, displayed histopathologic features similar to the primary gastric malignancies to a certain extent.

Conclusion: The possibility of metastatic involvement of stomach must be kept in mind while dealing with a gastric mass lesion in a cancer patient, even though the clinical and endoscopic features suggest primary gastric cancer. Our study points out the importance of conveying the information about medical history and clinical findings of the patients for correct pathologic differential diagnosis.

Keywords: Metastasis, Stomach, Metastatic carcinoma, Endoscopy, Gastric mass

\section{INTRODUCTION}

Metastatic disease involving the stomach is rare. The incidence is less than $5.4 \%$ based on the autopsy series of cancer patients (1-5). The cancers that are most commonly associated with gastric metastasis are malignant melanoma, lung adenocarcinoma, and invasive lobular carcinoma of the breast $(2,3,6)$.

Gastric metastases are associated with advanced stage and poor prognosis; however, the low incidence of this event makes management decisions difficult. The same reason also harbors the risk of misdiagnosis in routine pathology practice.

In our study, we reviewed archive materials of gastric biopsies as well as the clinical and endoscopic findings of gastric metastasis patients. Our aim was to create awareness for this rare event in pathology practice and highlight the entities that need to be taken into consideration for the differential diagnosis.

\section{MATERIALS and METHOD}

Our cohort consists of seventeen patients with histologically verified metastatic cancer in the stomach seen at the Istanbul University, Istanbul Faculty of Medicine Hospital between January 2007 and December 2017. Secondary hematolymphoid malignancies were excluded. Pathology reports and archive slides were reviewed. Clinical data of the patients were obtained from the medical records. The national database was used for the survival data. This is a retrospective archive study and does not include any study on live human or animal subjects by any of the authors. Therefore ethics committee approval was not sought.

\section{RESULTS}

\section{Demography and Tumor Types}

There were 12 female and 5 male patients in our cohort. The mean age was $57.41 \pm 12.99$ years. The most common malignancy metastatic to the stomach was invasive lobular carcinoma of the breast (6/17), followed by malignant 
melanoma (5/17). The rest of the cohort consisted of lung carcinomas (2/17) (1 adenocarcinoma, 1 squamous cell carcinoma (SCC)), serous ovarian carcinomas (2/17), colorectal adenocarcinoma (1/17) and undifferentiated high-grade soft tissue sarcoma (1/17) (Table I).

\section{Clinical Findings}

In our cohort, only three patients were symptomatic related to the metastatic lesion and required surgical intervention. One of the metastatic malignant melanoma patients presented with upper gastrointestinal bleeding. One of the invasive lobular carcinoma metastases caused gastric outflow obstruction that needed an emergency gastrectomy and the colonic adenocarcinoma metastatic to the stomach caused fistula formation between the pleural cavity and the stomach.

Invasive lobular carcinoma and malignant melanoma were the two most common malignancies with synchronous metastasis in our cohort. Synchronous metastatic sites for malignant melanoma were the axillary lymph nodes and bowel; for invasive lobular carcinoma they were bone and bowel; for colonic adenocarcinoma it was the liver, and for soft tissue sarcoma it was the heart. Both high-grade serous ovarian adenocarcinoma cases had peritoneal involvement. Peritoneal involvement was not present in the other malignancies in our cohort.

Information about the time period between the diagnosis of the primary tumor and gastric metastasis was available for 9 cases ( 1 malignant melanoma, 3 invasive lobular carcinomas, 1 SCC, 1 lung adenocarcinoma, 2 high-grade serous adenocarcinomas and 1 soft tissue sarcoma). The longest period was 60 months for two invasive lobular carcinoma and SCC cases. The shortest period was 7 months for malignant melanoma. For the other cases, the values were 36 months for high-grade serous adenocarcinomas, 24 months for lung adenocarcinoma and one invasive lobular carcinoma, and 12 months for soft tissue sarcoma.

\section{Endoscopic Findings}

The endoscopic findings of 14 patients out of 17 were obtained from the medical records. Two melanoma cases had multiple stomach lesions (Figure 1A,B) whereas the lesions in the other cases were solitary at the time of the diagnosis.

Table I: Clinicopathologic features of gastric metastasis cases.

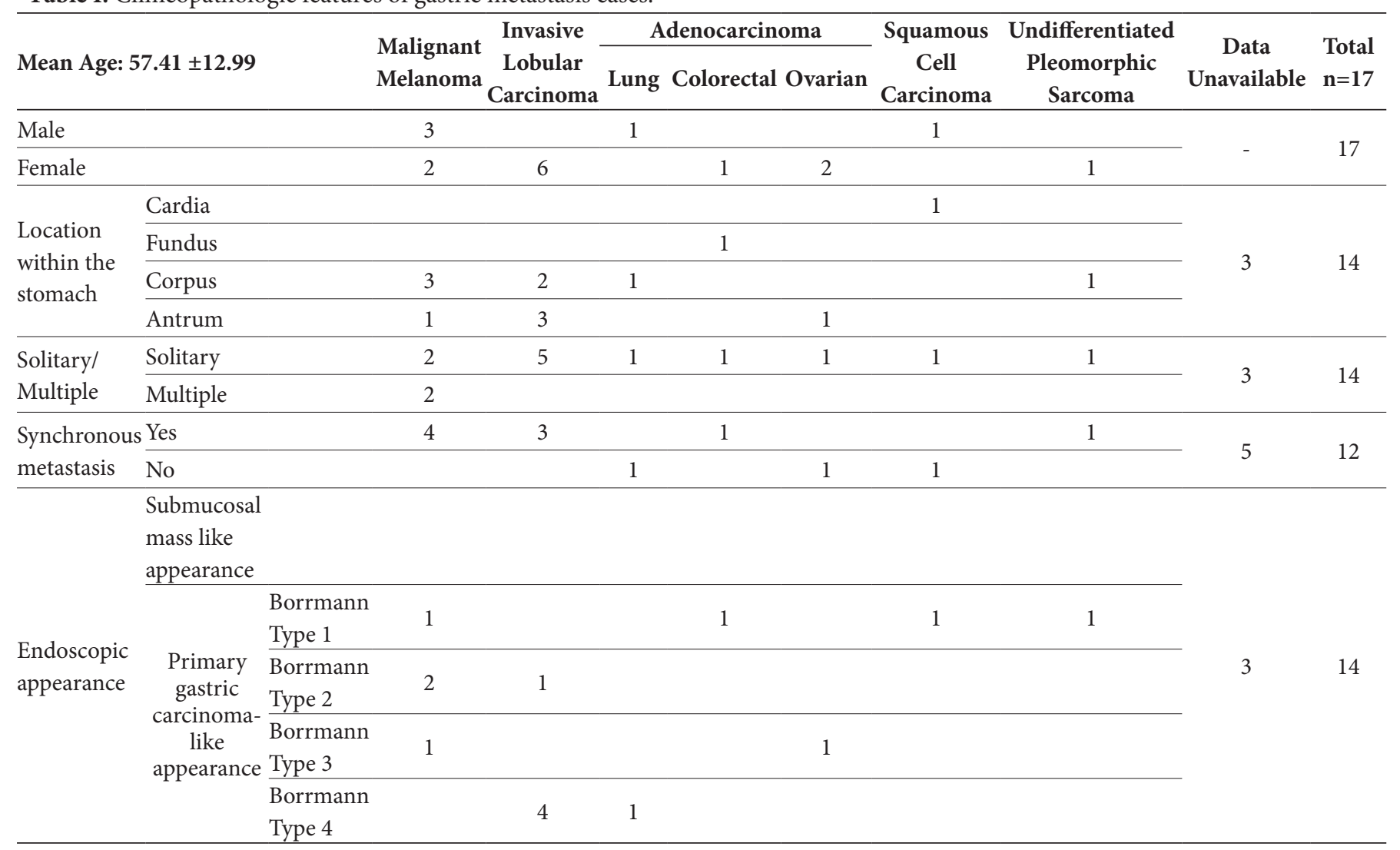



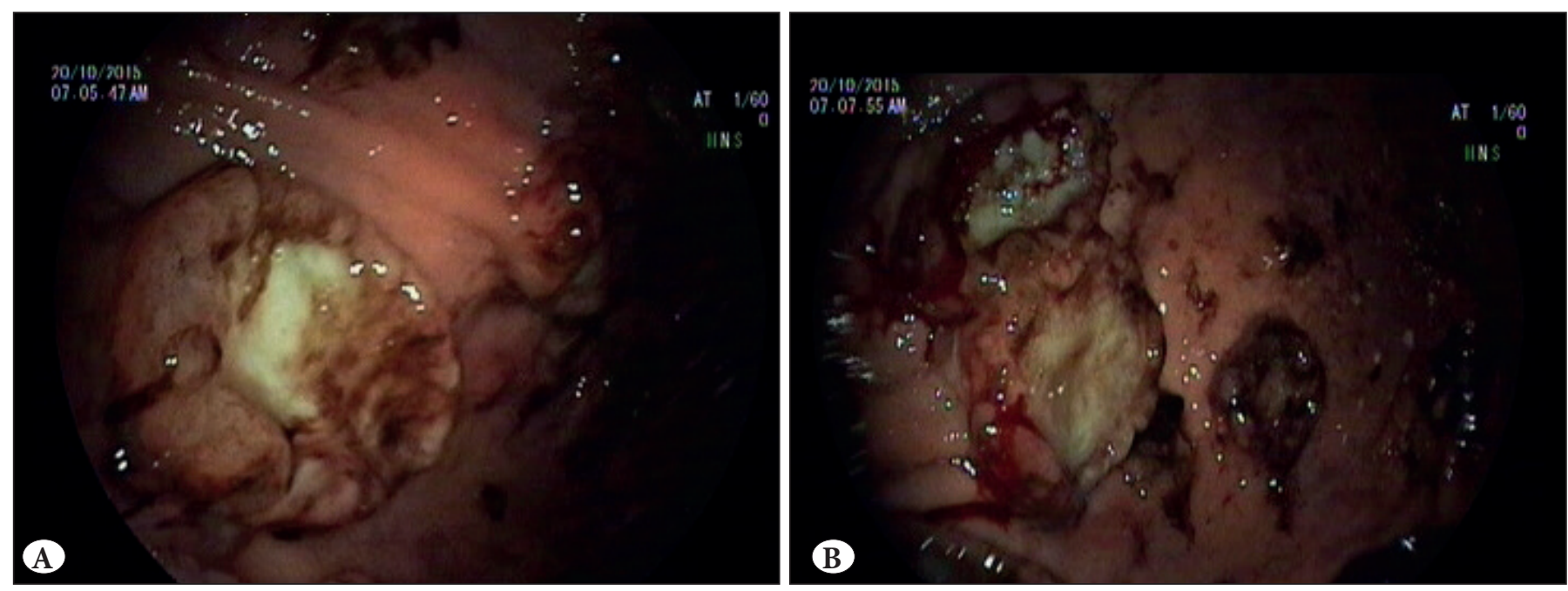

Figure 1: A,B) Endoscopic appearance of malignant melanoma metastasis in the gastric antrum. Multiple metastatic lesions displaying heterogenous pigmentation.

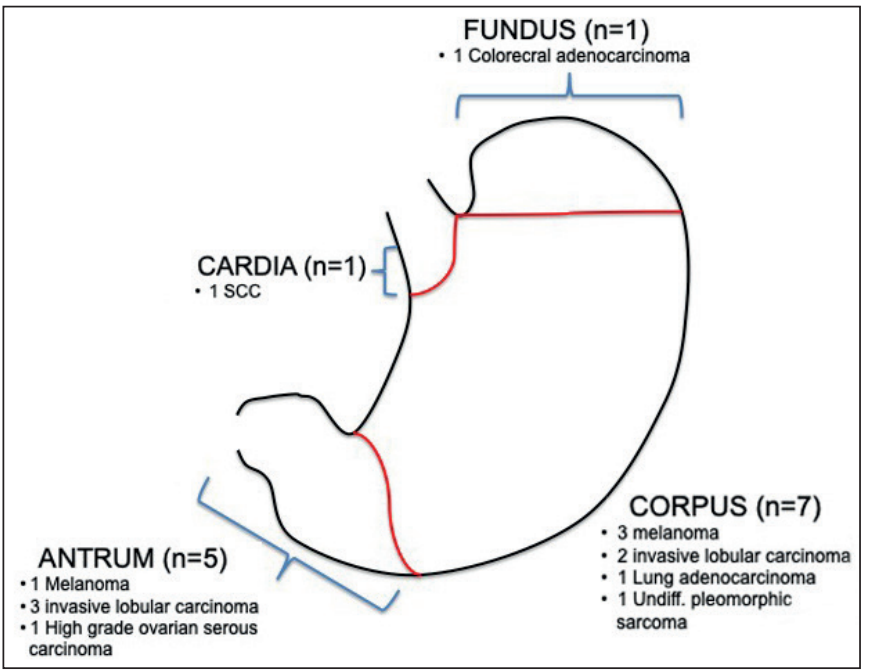

Figure 2: Anatomic distribution of gastric metastases

As we evaluated the distribution of the lesions, the lung SCC metastasis was located at the cardia; the colorectal carcinoma metastasis was located at the fundus; metastases of three melanomas, two invasive lobular carcinomas, one lung adenocarcinoma and sarcoma were located at the corpus and those of one melanoma, one serous ovarian carcinoma, and three invasive lobular carcinomas were located at the antrum (Table I) (Figure 2).

We detected that the endoscopic features resembled primary gastric carcinoma in all cases. Four cases (28\%) (one melanoma, one colorectal carcinoma, one lung SCC, and one sarcoma) presented as polypoid masses that fit into the Borrmann type 1 category. Three (21\%) of the lesions (2 melanomas and 1 invasive lobular carcinoma) were well-defined ulcerative lesions that fit into the Borrmann type 2 category. Two (14\%) of the lesions ( 1 melanoma and 1 serous ovarian carcinoma) were ulcerative lesions with infiltrating margins that fit into the Borrmann type 3 category. Five cases (35\%) (4 invasive lobular carcinomas and 1 lung adenocarcinoma) had a diffuse infiltrating appearance that fit into the Borrmann type 4 category (Table I) (Figure 3).

\section{Histopathological Findings}

Among the malignant melanoma cases, only one displayed prominent melanin pigment in neoplastic cells. The remaining four melanoma cases appeared as amelanotic. Four cases showed diffuse/interstitial growth pattern. Nested and pseudoglandular appearance was observed in only one. Nuclear pleomorphism was detected in all cases. Bizarre cells and rhabdoid morphology were observed in one case, prominent nucleoli in four, and intranuclear pseudoinclusions in two cases. All cases were positive for S100 protein, melan-A and HMB-45 (Figure 4A-F).

Metastases of epithelial malignancies displayed morphologic and immunohistochemical features similar to their primary tumors.

All invasive lobular carcinoma metastases displayed similar morphologic features (i.e. tumor cells appearing as single cells or forming cords). Intracytoplasmic lumen formation was detected in all cases. Three cases had prominent eosinophilic secretory material in the cytoplasm of tumor cells and other three cases had mucoid PAS positive material within the intracytoplasmic lumina (Figure 5A-F). Squamous cell carcinoma metastasis showed no keratinization and displayed poorly differentiated areas. 
The lung adenocarcinoma metastasis was composed of solid groups of tumor cells without any glandular formations and displayed cytokeratin 7 and thyroid transcription factor 1 (TTF-1) immunopositivity.

The colorectal adenocarcinoma metastasis showed the usual colorectal adenocarcinoma morphology with glands composed of columnar cells and necrotic debris in the glandular lumina. Tumor cells were cytokeratin 7 negative but cytokeratin 20, CDX2, and carcinoembryonic antigen (CEA) positive.

Both ovarian serous carcinoma cases were of the highgrade type.

In the metastatic sarcoma case, the primary tumor that had been in the gluteal region was composed of pleomorphic spindle cells devoid of any particular histologic pattern, and thorough immunohistochemical evaluation showed

\begin{tabular}{|c|c|c|c|}
\hline $\begin{array}{l}\text { Borrmann Type } 1 \\
\qquad(n=4)\end{array}$ & $\begin{array}{l}\text { Borrmann Type } 2 \\
(n=3)\end{array}$ & $\begin{array}{l}\text { Borrmann Type } 3 \\
(n=2)\end{array}$ & $\begin{array}{l}\text { Borrmann Type } 4 \\
\qquad(n=5)\end{array}$ \\
\hline $\begin{array}{l}\text { - } 1 \text { Malignant } \\
\text { melanoma } \\
\text { - } 1 \text { Colorectal } \\
\text { adenocarcinoma } \\
\text { - } 1 \text { SCC } \\
\text { - } 1 \text { Sarcoma }\end{array}$ & $\begin{array}{l}\text { - } 2 \text { Malignant } \\
\text { melanoma } \\
\text { - } 1 \text { Invasive } \\
\text { lobular } \\
\text { carcinoma }\end{array}$ & $\begin{array}{l}1 \text { Malignant } \\
\text { melanoma } \\
\text { - } 1 \text { High grade } \\
\text { ovarian } \\
\text { serous } \\
\text { carcinoma }\end{array}$ & $\begin{array}{l}\text { - } 4 \text { Invasive } \\
\text { lobular } \\
\text { carcinoma } \\
\text { - } 1 \text { Lung } \\
\text { adenocarcinoma }\end{array}$ \\
\hline
\end{tabular}

Figure 3: Macroscopic appearance of gastric metastases according to the Borrmann Classification
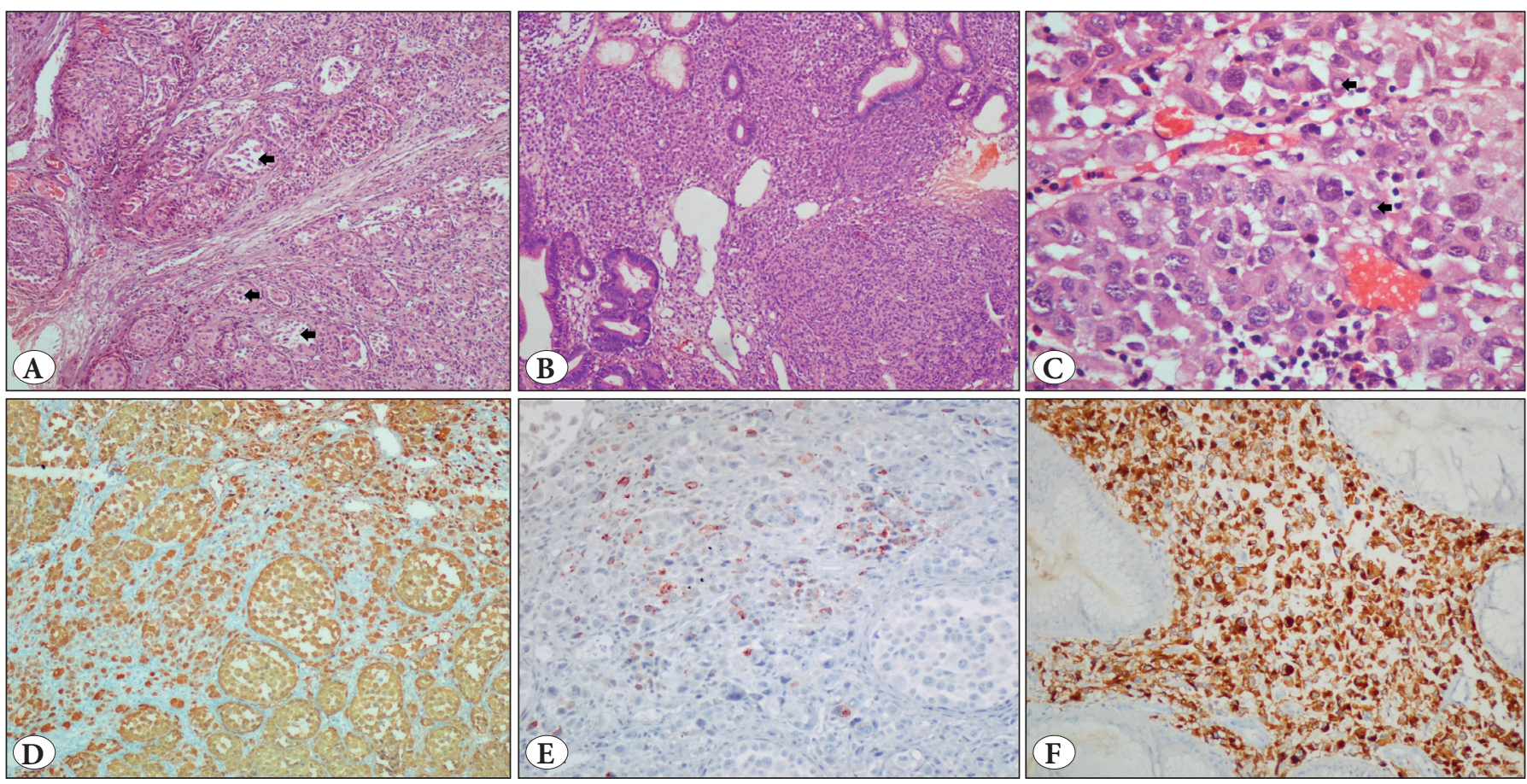

Figure 4: Malignant melanoma metastasis. A) Melanoma cells forming nests of varying sizes. Some nests display pseudoglandular pattern (arrows) (H\&E; x100). B) Neoplastic cells infiltrating the lamina propria. Neoplastic cells are small and show minimal pleomorphism (H\&E; x100). C) Melanoma cells showing prominent nuclear pleomorphism and intranuclear inclusions (arrows) (H\&E; 4400$)$.

D) Neoplastic cells displaying diffuse S100 protein immunoreactivity (IHC; x100). E) Focal cytoplasmic HMB-45 immunoreactivity (IHC; x100). F) Diffuse cytoplasmic Melan A immunoreactivity (IHC; x200). 

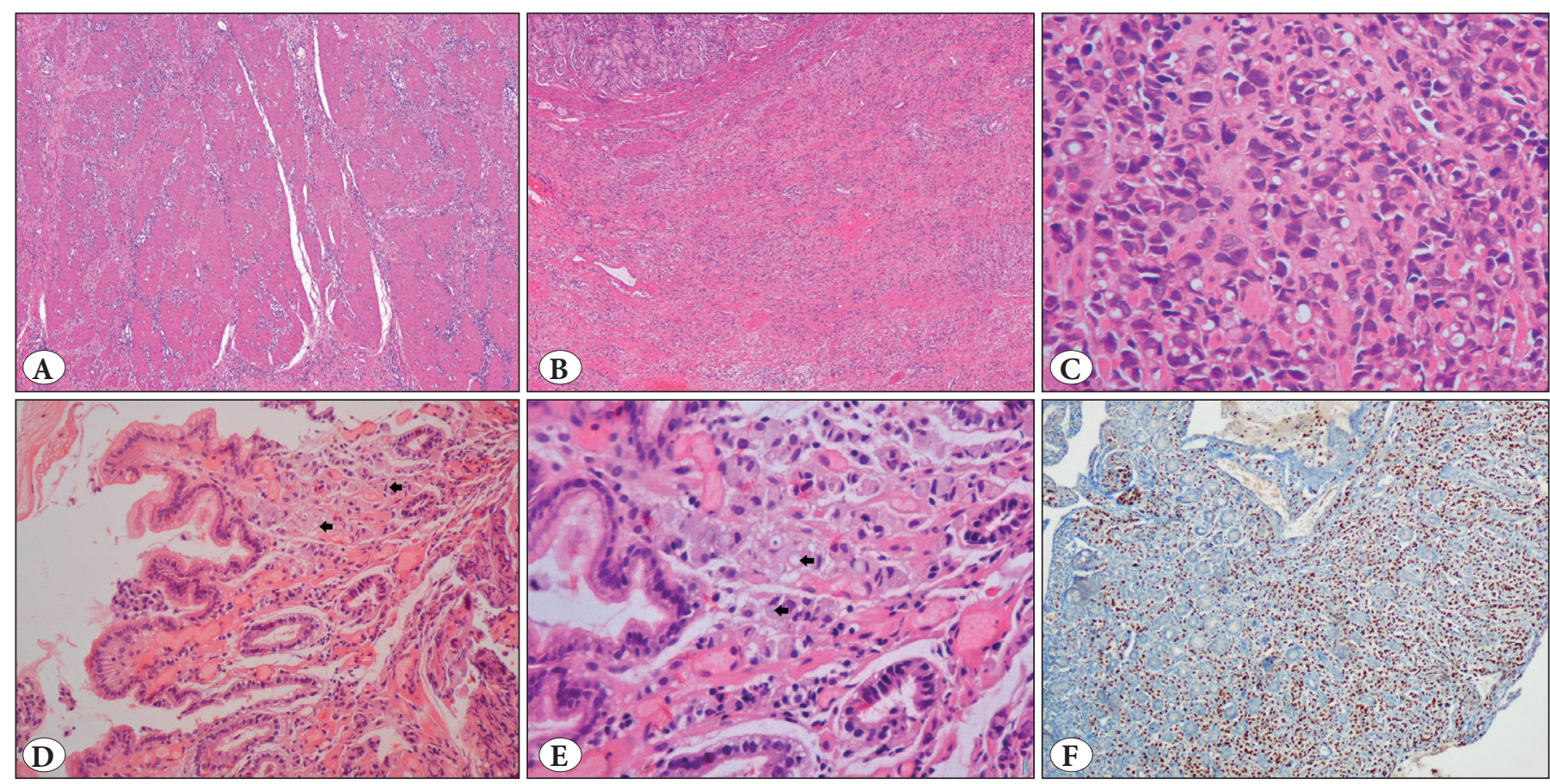

Figure 5: Invasive lobular carcinoma metastasis to the stomach. A) Diffuse infiltration of neoplastic cells within the muscle layer (H\&E; x40). B) Submucosal infiltration of neoplastic cells (H\&E; x40). C) Neoplastic cells with intracytoplasmic lumina containing eosinophilic globular material (H\&E; x400). D) Neoplastic cells display subtle nuclear atypia forming strands in the lamina propria (arrows) (H\&E; $\mathrm{x} 200$ ). E) The same neoplastic cells seen in Figure 1D, mimicking signet ring cells with intracytoplasmic mucoid material and lumen formation (arrows) (H\&E; x400). F) GATA3 nuclear immunopositivity in neoplastic cells (IHC; x200).

no particular line of differentiation. Its gastric metastasis had spindle cells in a myxoid background and was more hypocellular than its primary.

\section{DISCUSSION}

The stomach is an unusual site for metastasis. The incidence rate of metastatic stomach masses is $0.2-0.8 \%(3-5)$. However, the exact incidence is unknown, as the stomach is not routinely evaluated for metastatic cancer. Patients with gastric metastasis are usually asymptomatic (7). Symptomatic patients usually have stomach pain, nausea, vomiting, bleeding, and symptoms related to obstruction (2).

As we stated previously, gastric metastasis is a late event and associated with an advanced stage (1). In our cohort, 9 patients had biopsy-proven metastases other than in the stomach. Although we do not have the data for all cases, the time period between the first diagnosis of the primary tumor and the gastric metastasis was longest for SCC and invasive lobular carcinoma cases and shortest for malignant melanoma cases. This feature can be attributed to the overall aggressiveness of the mentioned neoplasm.

We encountered solitary gastric metastatic lesions more commonly than multiple lesions. This finding correlates with another study in the literature (2). Macroscopic appearance of the lesions was similar to the primary gastric tumors. Lobular carcinoma metastasis in particular seems to have a tendency to create the linitis plastica appearance. Four out of 6 lobular carcinoma metastases displayed an endoscopic appearance mimicking the diffuse infiltrative type of primary gastric carcinoma. This feature was shared with the lung adenocarcinoma metastasis as well. Other metastatic masses showed various endoscopic appearances and a polypoid mass lesion seemed the most common one. Although the exact relationship between tumor biology and macroscopic appearance of metastatic masses is not fully understood, the discohesive nature of the lobular carcinoma cells can be pointed out as the reason for diffuse infiltrative growth pattern in metastatic site (6). As the metastatic masses are more commonly presented as solitary mass lesions that resemble any of the Borrmann types of primary gastric adenocarcinoma, it is sometimes difficult to differentiate a metastatic gastric mass from a primary gastric malignancy endoscopically. The endoscopist, as well as the pathologist, should be well aware of the possibility of metastases to the stomach - although rare - while dealing with a cancer patient with a gastric mass. 
Theoretically, any tumor might metastasize to the stomach. Malignant melanoma, invasive lobular breast carcinoma and lung carcinomas are the most commonly reported primaries as stated before $(2,3,6)$. However, gastric metastatic tumors originating from the kidney, pancreas, esophagus, skin, testis, cervix, and colon have also been reported $(1,2,8)$.

Invasive lobular carcinoma deserve specialattention because of both the macroscopic and microscopic pathological findings, which are sometimes indistinguishable from those of primary gastric carcinoma (9-13). The clinical history plays an important role in differentiating between primary and metastatic masses. However, there are cases that the metastatic lesion was diagnosed before the primary (14). An immunohistochemical panel consisting of estrogen receptor (ER), progesterone receptor (PR), gross cystic disease fluid protein (GCDFP-15), mammoglobin, and GATA3 can be useful in differentiating invasive lobular breast carcinoma (15-19). However, one should be well aware of the fact that weak ER positivity does not rule out gastric adenocarcinoma $(20,21)$. Yokozaki et al. detected that immunexpression of ER was a more frequent finding in poorly differentiated gastric adenocarcinoma than that of its well differentiated counterpart and immunoreactivity was not sex-related (21). However, ER was found to be negative in all gastric adenocarcinomas in a European study (22). Because of the morphologic similarities between primary diffuse type gastric carcinoma and invasive lobular carcinoma of the breast, the possibility of a metastatic breast carcinoma - although low - must be kept in mind for the differential diagnosis.

Malignant melanoma has diverse morphologic appearances. We found that the tumor cells in all melanoma cases had marked nuclear pleomorphism and prominent nucleoli. Clinical history plays an important role in diagnosing metastatic malignant melanoma in the stomach but the possibility of an occult melanoma or total regression of primary lesion must be kept in mind. Melanomas can be separated from gastric carcinomas by their S100 protein expression staining coupled with their lack of keratin immunoreactivity. More specific melanoma markers such as Melan-A, HMB-45, SRY-related HMG-box 10 (SOX-10), microphthalmia-associated transcription factor (MiTF) and tyrosinase, should be used together with S100 protein for accurate differential diagnosis. As melanomas can also be immunoreactive to c-kit/CD117 antibodies, a panel approach is warranted to exclude epitheloid gastrointestinal stromal tumor (GIST). Melan-A can be positive on GISTs as well (23).
About $31-38 \%$ of ovarian cancer patients develop distant metastasis during the course of the disease $(24,25)$. The most common ovarian adenocarcinoma subtype metastatic to the stomach is serous adenocarcinoma (26). Because of its tendency to spread through peritoneal surfaces, gastric metastasis of ovarian serous adenocarcinoma without peritoneal involvement is extremely rare (24-26). Both of our metastatic ovarian carcinoma cases were serous adenocarcinomas and had gastric peritoneal surface involvement.

There are occasional reports of primary gastric undifferentiated sarcomas (27). However, metastatic sarcomas in the stomach are extremely rare (28-30). In our literature review, we found 28 cases of sarcoma metastasis to stomach between 1983 and 2016 in the Pubmed database (Table II). We revealed that the primary site was the lower extremity in 11 out of 28 cases; however, the location of the primary had no impact on the prediction of gastric metastatic potential when all 28 metastatic sarcoma cases were taken into account. The primary lesion was located at the right gluteal area in our only metastatic sarcoma case. When we look at the distribution of the metastatic lesions in our literature review, 12 of the metastatic lesions were located at the curvatures of the stomach (1 lesser and 11 greater). Akatsu et al. suggests that this distribution seems to reflect the tendency of hematogenous spread of sarcomas occurs through the gastroduodenal or gastroepiploic vessels (31). The metastatic gastric lesion in our sarcoma case was located in the lesser curvature at the cardia-corpus junction.

As we stated previously, information about the clinical history of the patient is crucial in the differential diagnosis. None of the morphologic features in our cohort was pathognomonic except those of the pigmented melanoma case. All other cases can easily be misdiagnosed as poorly differentiated adenocarcinoma without the clinical information. This problem becomes more apparent for invasive lobular breast carcinoma cases because of their almost identical morphologic features with poorly cohesive gastric carcinoma.

In this study we highlighted the similarities of primary gastric cancer and metastatic malignancies to the stomach in endoscopic biopsies. There are other studies with similar or larger cohorts, including autopsy series, in the literature $(2,8,58,59)$. These studies mainly focus on epidemiological, endoscopic and macroscopic aspects of the metastatic lesions of the stomach without going into the details of the microscopic features of the cases. In this study, we analyzed the histologic features of the metastases and potential 
Table II: Literature review of metastatic sarcoma cases.

\begin{tabular}{|c|c|c|c|c|c|c|}
\hline Authors & Age & Sex & Histologic Subtype & Primary Site & $\begin{array}{l}\text { Duration } \\
\text { (Months) }\end{array}$ & Site within stomach \\
\hline Akatsu et al. (2006) (31) & 75 & Male & MFH & Back & 24 & Antrum \\
\hline Dent et al. (2010) (32) & 60 & Male & $\begin{array}{l}\text { Undifferentiated } \\
\text { pleomorphic } \\
\text { sarcoma }\end{array}$ & $\begin{array}{l}\text { Left posterior } \\
\text { shoulder }\end{array}$ & 6 & Greater curvature \\
\hline $\begin{array}{l}\text { Overberg-Schmidt et al. } \\
\text { (1999) (33) }\end{array}$ & 11 & Female & Osteosarcoma & Femur & 14 & Posterior gastric wall \\
\hline Strong et al. (2007) (34) & 17 & Male & Osteosarcoma & Femur & 30 & Antrum \\
\hline Horiuchi et al. (2010) (35) & 18 & Male & Osteosarcoma & Humerus & 30 & Corpus \\
\hline Urakawa et al. (2013) (36) & 73 & Male & Osteosarcoma & Sternum & 11 & Corpus \\
\hline Moses et al. (2013) (37) & 17 & Male & Osteosarcoma & Leg & 14 & Fundus \\
\hline $\begin{array}{l}\text { Abe et al. } \\
(2016)(38)\end{array}$ & 78 & Female & Leiomyosarcoma & Heart, left atrium & 24 & - \\
\hline Costa et al. (2016) (39) & 52 & Female & Leiomyosarcoma & Uterus & 84 & $\begin{array}{c}\text { Corpus, greater } \\
\text { curvature }\end{array}$ \\
\hline Nakajima et al. (2005) (40) & 61 & Male & Leiomyosarcoma & Leg & 24 & Corpus \\
\hline Ferrozi et al. (1994) (41) & 50 & Female & Leiomyosarcoma & Retroperitoneum & 6 & Greater curvature \\
\hline Ferrozi et al. (1994) (41) & 55 & Male & Leiomyosarcoma & Retroperitoneum & 24 & $\begin{array}{l}\text { Antrum, greater } \\
\text { curvature }\end{array}$ \\
\hline Obata et al. (1993) (42) & 58 & Female & Angiosarcoma & Left hip & 2 & $\begin{array}{l}\text { Corpus, greater } \\
\text { curvature }\end{array}$ \\
\hline Kim et al. (2005) (43) & 54 & Male & Angiosarcoma & Liver & 3 & Antrum, cardia \\
\hline Okabayashi et al. (1993) (44) & 84 & Male & Angiosarcoma & Thoracic wall & 11 & Antrum \\
\hline Konishi et al. (1994) (45) & 34 & Female & Chondrosarcoma & Popliteal fossa & 84 & $\begin{array}{l}\text { Immediately below } \\
\text { GEJ }\end{array}$ \\
\hline Chuan et al. (2016) (46) & 56 & Male & Synovial sarcoma & Thigh & 12 & Incisura angularis \\
\hline Choi et al. (2016) (47) & 44 & Female & Phylloides tumor & Breast & 60 & Lesser curvature \\
\hline Sonobe et al. (1980) (48) & 39 & Male & MFH & Maxillary sinus & 12 & Corpus \\
\hline Adams et al. (1983) (49) & 70 & Female & MFH & Upper thigh & 36 & Greater curvature \\
\hline Yasuda et al. (1985) (50) & 66 & Male & $\mathrm{MFH}$ & Lung & - & $\begin{array}{c}\text { Body, greater } \\
\text { curvature }\end{array}$ \\
\hline Fujii et al. (1993) (51) & 77 & Male & $\mathrm{MFH}$ & Lung & - & Antrum \\
\hline Okada et al. (1995) (52) & 67 & Female & $\mathrm{MFH}$ & Femur & - & $\begin{array}{c}\text { Body, greater } \\
\text { curvature }\end{array}$ \\
\hline Ohuchi et al. (1997) (53) & 62 & Male & $\mathrm{MFH}$ & Ethmoid sinus & - & $\begin{array}{l}\text { Body, antrum, greater } \\
\text { curvature }\end{array}$ \\
\hline Hisai et al. (1998) (54) & 64 & Male & $\mathrm{MFH}$ & Knee & - & $\begin{array}{c}\text { Antrum, greater } \\
\text { curvature }\end{array}$ \\
\hline Nishida et al. (1998) (55) & 69 & Male & MFH & Mesentery & - & - \\
\hline Kato et al. (2002) (56) & 70 & Male & MFH & Gallbladder & 29 & $\begin{array}{l}\text { Antrum, greater } \\
\text { curvature }\end{array}$ \\
\hline Ibanez et al. (2011) (57) & 39 & Male & $\mathrm{MFH}$ & Thigh & 60 & Antrum, corpus \\
\hline
\end{tabular}

MFH: Malignant fibrous histiocytoma, GEJ: Gastroesophageal junction

microscopic pitfalls in the differential diagnosis as well as the endoscopic and macroscopic findings.

Despite its low prevalence, the possibility of gastric metastasis must be kept in mind for gastric masses with unusual macroscopic and microscopic features. Our study also points out the importance of the clinical history and clinical information in the decision-making process of pathological differential diagnosis. 


\section{CONFLICT of INTEREST}

The authors declare no conflict of interest.

\section{FUNDING}

None

\section{AUTHORSHIP CONTRIBUTIONS}

Concept: AYA, MG, Design: AYA, MG, Data collection or processing: AYA, İÖ, AFKG, BÇ, EA, SV, Analysis or Interpretation: AYA, MB, MG, Literature search: AYA, MB, Writing: AYA, MG, Approval: MG, SV.

\section{REFERENCES}

1. Donahue-Iacobuzio C, Groisman GM. Secondary tumors of the stomach. In: Bosman FT, Carneiro F, Hruban RH, Theise ND eds. World Health Organization Classification of Tumour: Pathology and Genetics of Tumours of the Digestive System. Lyon, France: IARC Press; 2010:79-80 p.

2. Oda, Kondo H, Yamao T, Saito D, Ono H, Gotoda T, Yamaguchi H, Yoshida S, Shimoda T. Metastatic tumors to the stomach: Analysis of 54 patients diagnosed at endoscopy and 347 autopsy cases. Endoscopy. 2001;33:507-10.

3. Green LK. Hematogenous metastases to the stomach. A review of 67 cases. Cancer. 1990;65:1596-600.

4. Davis GH, Zollinger RW. Metastatic melanoma of the stomach. Am J Surg. 1960;99:94-6.

5. Higgins PM. Pyloric obstructions due to a metastatic deposit from carcinoma of the bronchus. Can J Surg. 1962;5:438-41.

6. Taal BG, Peterse H, Boot H. Clinical presentation, endoscopic features, and treatment of gastric metastases from breast carcinoma. Cancer. 2000;89:2214-21.

7. Alpar S, Kurt OK, Ucar N, Orsel O, Aydog G, Kurt B. A case of squamous cell lung carcinoma with gastric metastasis. South Med J. 2006;99:1313-4.

8. Campoli PM, Ejima FH, Cardoso DM, Silva OQ, Santana Filho JB, Queiroz Barreto PA, Machado MM, Mota ED, Araujo Filho JA, Alencar Rde C, Mota OM. Metastatic cancer to the stomach. Gastric Cancer. 2006;9:19-25.

9. Raju U, Ma CK, Shaw A. Signet ring variant of lobular carcinoma of the breast: A clinicopathologic and immunohistochemical study. Mod Pathol. 1993;6:516-20.

10. Harris M, Howell A, Chrissohou M, Swindell RI, Hudson M, Sellwood RA. A comparison of the metastatic pattern of infiltrating lobular carcinoma and infiltrating duct carcinoma of the breast. Br J Cancer. 1984;50:23-30.

11. Cormier WJ, Gaffey TA, Welch JM, Welch JS, Edmonson JH. Linitis plastica caused by metastatic lobular carcinoma of the breast. Mayo Clin Proc. 1980;55:747-53.

12. Hartmann WH, Sherlock P. Gastroduodenal metastases from carcinoma of the breast. An adrenal steroid-induced phenomenon. Cancer. 1961;14:426-31.
13. Yoshida Y. Metastases and primary neoplasms of the stomach in patients with breast cancer. Am J Surg. 1973;125:738-43.

14. Kobayashi T, Shibata K, Matsuda Y, Tominaga S, Komoike Y, Adachi S. A case of invasive lobular carcinoma of the breast first manifesting with duodenal obstruction. Breast Cancer. 2004;11:306-8.

15. O’Connell FP, Wang HH, Odze RD. Utility of immunohistochemistry in distinguishing primary adenocarcinomas from metastatic breast carcinomas in the gastrointestinal tract. Arch Pathol Lab Med. 2005;129:338-47.

16. Shimizu M, Matsumoto T, Hirokawa M, Shimozuma K, Manabe T. Gastric metastasis from breast cancer: A pitfall in gastric biopsy specimens. Pathol Int. 1998;48:240-1.

17. Wang NP, Zee S, Zarbo RJ, Bacchi C, Gown A. Coordinate expression of cytokeratins 7 and 20 defines unique subsets of carcinomas. Appl Immunohistochem. 1995;3: 99-107

18. Sangoi AR, Shrestha B, Yang G, Mego O, Beck AH. The novel marker GATA3 is significantly more sensitive than traditional markers mammaglobin and GCDFP15 for identifying breast cancer in surgical and cytology specimens of metastatic and matched primary tumors. Appl Immunohistochem Mol Morphol. 2016;24:229-37.

19. Yang Y, Lu S, Zeng W, Xie S, Xiao S. GATA3 expression in clinically useful groups of breast carcinoma: A comparison with GCDFP15 and mammaglobin for identifying paired primary and metastatic tumors. Ann Diagn Pathol. 2017;26:1-5.

20. Harrison JD, Morris DL, Ellis IO, Jones JA, Jackson I. The effect of tamoxifen and estrogen receptor status on survival in gastric carcinoma. Cancer. 1989;64:1007-10.

21. Yokozaki H, Takekura N, Takanashi A, Tabuchi J, Haruta R, Tahara E. Estrogen receptors in gastric adenocarcinoma: A retrospective immunohistochemical analysis. Virchows Arch A Pathol Anat Histopathol. 1988;413:297-302.

22. Chaubert P, Bouzourene H, Saraga E. Estrogen and progesterone receptors and $\mathrm{pS} 2$ and ERD5 antigens in gastric carcinomas from the European population. Mod Pathol. 1996;9:189-93.

23. Guler ML, Daniels JA, Abraham SC, Montgomery EA. Expression of melanoma antigens in epithelioid gastrointestinal stromal tumors: A potential diagnostic pitfall. Arch Pathol Lab Med. 2008;132:1302-6.

24. Dauplat J, Hacker NF, Nieberg RK, Berek JS, Rose TP, Sagae S. Distant metastases in epithelial ovarian carcinoma. Cancer. 1987;60:1561-6.

25. Cormio G, Rossi C, Cazzolla A, Resta L, Loverro G, Greco $\mathrm{P}$, Selvaggi L. Distant metastases in ovarian carcinoma. Int J Gynecol Cancer. 2003;13:125-9.

26. Mizuguchi K, Minato H, Yoshida I, Iwadare J, Kayahashi K, Mitani Y, Watanabe K. Solitary gastric metastasis from a stage IA serous ovarian carcinoma: A case report with literature review. Intern Med. 2017;56:915-9.

27. Burningham Z, Hashibe M, Spector L, Schiffman JD. The epidemiology of sarcoma. Clin Sarcoma Res. 2012;2:14.

28. Lawrence W Jr, Donegan WL, Natarajan N, Mettlin C, Beart R, Winchester D. Adult soft tissue sarcomas. A pattern of care survey of the American College of Surgeons. Ann Surg. 1987;205:34959. 
29. Coindre JM, Terrier P, Guillou L, Le Doussal V, Collin F, Ranchère D, Sastre X, Vilain MO, Bonichon F, N'Guyen Bui B. Predictive value of grade for metastasis development in the main histologic types of adult soft tissue sarcomas: A study of 1240 patients from the French Federation of Cancer Centers Sarcoma Group. Cancer. 2001;91:1914-26.

30. Levine EA. Prognostic factors in soft tissue sarcoma. Semin Surg Oncol. 1999;17:23-32.

31. Akatsu Y, Saikawa Y, Kubota T, Kiyota T, Nakamura R, Akatsu T, Takahashi T, Yoshida M, Otani Y, Kumai K, Kitajima M. Metastatic gastric cancer from malignant fibrous histiocytoma: Report of a case. Surg Today. 2006;36:385-9.

32. Dent LL, Cardona CY, Buchholz MC, Peebles R, Scott JD, Beech DJ, Ballard BR. Soft tissue sarcoma with metastasis to the stomach: A case report. World J Gastroenterol. 2010;16:5130-4.

33. Overberg-Schmidt US, Baumgarten E, Bassir C, Becker M, Unger M, Henze G. The stomach and pulmonary interlobular space as unusual sites of osteosarcoma. Pediatr Hematol Oncol. 1999;16:61-6.

34. Strong VE, Shalkow J, Antonescu CR, Meyers P, La Quaglia MP. Osteosarcoma with delayed metastasis to the stomach. J Pediatr Surg. 2007;42:737-9.

35. Horiuchi K, Susa M, Mukai M, Nishimoto K, Suzuki Y, Nakayama R, Hosaka S, Yabe H, Toyama Y, Morioka H. Osteosarcoma with metastasis to the stomach. J Orthop Sci. 2010;15:265-8.

36. Urakawa H, Tsukushi S, Tsurudome I, Hirata A, Arai E, Kozawa E, Futamura N, Miyahara R, Ishiguro N, Nishida Y. Metastasis of osteosarcoma to stomach made clinically evident by hematemesis: A case report. World J Surg Oncol. 2013;11:48.

37. Moses J, Gibson N, Plesec T, Plautz G, Kay M, Soldes O. Metastatic osteosarcoma to the stomach and ascending colon in a pediatric patient causing gastrointestinal hemorrhage. J Pediatr Surg. 2013;48:e1-3.

38. Abe K, Seo K, Yagi M, Sasajima Y, Yagi T, Inaba T, Fukushima R. Gastrointestinal metastasis of cardiac leiomyosarcoma. Endoscopy. 2016;48:E349-E350.

39. Costa M, Ivanova E, Esteves J. Upper gastrointestinal bleeding due to gastric metastasis from a primary uterine leiomyosarcoma. Acta Clin Belg. 2016;71:271-2.

40. Nakajima Y, Kakizaki S, Kanda D, Shimada Y, Sohara N, Sato $\mathrm{K}$, Takagi $\mathrm{H}$, Mori M, Watanabe $\mathrm{H}$. Pancreatic and gastric metastases of leiomyosarcoma arising in the left leg. Int J Clin Oncol. 2005;10:342-7.

41. Ferrozzi F, Bova D, Garlaschi G. Gastric metastases from retroperitoneal leiomyosarcoma. Abdom Imaging. 1994;19:298300.

42. Obata S, Mizutani J, Miura K, Kimura K, Maeda K, Fujioka Y, Matsumoto Y. Gastrointestinal metastases of an angiosarcoma. Endoscopy. 1993;25:438.

43. Kim TO, Kim GH, Heo J, Kang DH, Song GA, Cho M. Metastasis of hepatic angiosarcoma to the stomach. J Gastroenterol. 2005;40:1003-4.

44. Okabayashi K, Hanagiri T, Noda Y, Ozaki S, Shiraishi T, Mitsudomi T, Okamura T, Hamada T, Shirakusa T. Angiosarcoma of the chest wall with a gastric metastasis. Thorac Cardiovasc Surg. 1993;41:318-20.
45. Konishi H, Isetani K, Satoh T, Fukuda S, Kodama T, Kashima K. A case of metastatic chondrosarcoma of the stomach. J Gastroenterol. 1994;29:495-500.

46. Samuel T, Norly S, Ros'aini P. Gastric ulcer that turned out to be metastasis of a synovial sarcoma: A case report and literature review. Med J Malaysia. 2016;71:363-5.

47. Choi DI, Chi HS, Lee SH, Kwon Y, Park SY, Sim SH, Park IH, Lee KS. A rare case of phyllodes tumor metastasis to the stomach presenting as anemia. Cancer Res Treat. 2017;49:846-9.

48. Sonobe H, Taguchi K, Motoi M, Ogawa K, Matsumura M, Ohsaki K. Malignant fibrous histiocytoma of the maxillary sinus. Acta Pathol Jpn. 1980;30:79-89.

49. Adams HW, Adkins JR, Rehak EM. Malignant fibrous histiocytoma presenting as a bleeding gastric ulcer. Am J Gastroenterol. 1983;78:212-3.

50. Yasuda Y, Kosaba S, Hatakenaka R, Matsubara Y, Funatsu T, Ikeda S. A case report of primary malignant fibrous histiocytoma of the lung with metastasis to the stomach. Nihon Kyobu Geka Gakkai Zasshi. 1987;35:504-9.

51. Fujii K, Matsushita T, Makino T. A case report of primary malignant fibrous histiocytoma of the lung with metastasis to the stomach (in Japanese). Iryo. 1993;47:224.

52. Okada C, Nagao S, Tokunaga T, Sasaki J, Aono S, Fukushima Y. A case of the malignant fibrous histiocytoma with gastric involvement (in Japanese with English abstract). Gastroenterol Endosc. (Jpn Gastroenterol Endoscopy Soc) 1995;38:1648-53.

53. Ohuchi T, Iwaki H, Ikeda T, Satoh M, Narimatsu H, Yasuhiko Y. A case of primary malignant fibrous histiocytoma of the ethmoidal sinus with metastasis to the gastric mucosa (in Japanese with English abstract). Gan no Rinsho. (Jpn J Cancer Clin) 1997;43: 255-61.

54. Hisai H, Saitoh T, Sasaki H, Takahashi Y, Katahira T, Matsuyama T. A case of primary malignant fibrous histioctytoma of the knee with gastric metastasis (in Japanese with English abstract). Gastroenterol Endoscopy. (Jpn Gastroentelol Endoscopy Soc) 1998;40: 1034-9.

55. Nishida T, Tanomichi D, Ogawa T, Koama K, Uesugi T, Morri K. A case of malignant fibrous histiocytoma with gastric metastasis (in Japanese). Nissekiigaku (Jpn Red Cross Med J). 1998;50:98.

56. Kato T, Kojima T, Shimizu T, Sasaki H, Abe M, Okushiba S, Kondo S, Kato $\mathrm{H}$, Sato $\mathrm{H}$. Inflammatory malignant fibrous histiocytoma of the gallbladder: Report of a case. Surg Today. 2002;32:81-5.

57. Contreras Ibáñez JA, Navas García N, Díaz Gómez L. Mestastatic gastric cancer from malignant fibrous histiocytoma. Rev Esp Enferm Dig. 2011;103:44-6.

58. Menuck LS, Amberg JR. Metastatic disease involving the stomach. Am J Dig Dis. 1975;20:903-13.

59. Haendchen Bento L, Kazuyoshi Minata M, Pires Batista C, Martins BDC, Lenz Tolentino LH, Scomparim RC, Shiguehissa Kawaguti F, Gusmon de Oliveira CC, Simas de Lima M, Naschold Geiger S, Ryoka Baba E, Safatle-Ribeiro A, Ribeiro U Jr, MalufFilho F. Clinical and endoscopic aspects of metastases to the gastrointestinal tract. Endoscopy. 2019;51:646-52. 